\title{
Head injuries in helmeted child bicyclists
}

\author{
Guy Grimard, Terry Nolan, John B Carlin
}

\begin{abstract}
Objective-Todetermine the characteristics and the severity of head and facial injuries to helmeted child bicyclists, and whether the helmet contributed to the injury, and to study factors related to bicycle accidents.
\end{abstract}

Design-Retrospective review of two case series. Children sustaining head injury while not wearing helmets were studied as a form of reference group.

Setting-Large paediatric teaching hospital.

Subjects-34 helmeted child bicyclists and 155 non-helmeted bicyclists, aged 5-14 years.

Main outcome measures-Number of injuries, type of injuries, injury severity score, deaths, and accident circumstances.

Results $-79 \%$ of the head injuries of the helmeted child group were mild and two thirds of these had facial injuries. Children in the helmet group were in a greater proportion of bike-car collisions than the no helmet group and at least $15 \%$ of the helmets were lost on impact. There were no injuries secondary to the helmet.

Conclusions-Most of the head injuries sustained by the helmeted children were of mild severity and there was no evidence to suggest that the helmet contributed to injury. Nevertheless, consideration should be given to designing a facial protector for the bicycle helmet and to improvement of the fastening device.

(Injury Prevention 1995; 1: 21-25)

Keywords: head, bicyclists, helmet.

In Victoria, population based injury surveillance has revealed that bicycle injuries are the second most frequent sport and recreational injury. ${ }^{1}$ About $1 \%$ of all children aged between 5 and 14 years are brought to hospital each year because of injuries related to a bicycle accident. ${ }^{2}$ The great majority of deaths from bicycle related injuries are the result of head trauma. ${ }^{3-8}$ One study in Canada showed that bicycling represents the primary cause of head injury in children'; in an Australian study it was ranked second after falls $\mathrm{s}^{\mathrm{1}}$; and in a Californian study third after non-vehicle and motor vehicle accidents. ${ }^{11}$

In an attempt to improve head protection of bicyclists and thereby reduce further the number of head injury related deaths, especially in children, the state Government of
Victoria adopted a law requiring bicyclists of all ages to wear an approved safety helmet in July $1990 .^{12}$ Prior to this, high rates of voluntary helmet wearing (around $60 \%$ ) had already been achieved. ${ }^{13}$

Although there is good evidence of a substantial reduction in head injuries following high levels of voluntary helmet wearing and subsequently very high levels after mandated wearing, it is clear that head injuries still occur to helmeted cyclists. The purpose of this study was to examine the nature, characteristics, and severity of head injuries to helmeted cyclists in the hope that the information gathered would provide clues for improved design. More particularly, as helmets were being worn by most child riders, we wished to determine whether unexpectedly high rates of injury were occurring in helmeted cyclists, and whether the helmets themselves were contributing to other, preventable head injuries. In pursuit of these objectives we studied factors related to, and the circumstances surrounding, the bicycle accident, together with the characteristics and severity of the ensuing injuries. We were also interested in the degree to which head injuries in helmeted cyclists could be associated with more severe collisions or impacts. With a hospital sample of injured bicyclists, an appropriate control group is virtually impossible to assemble because an unknown number of helmeted cyclists will have been involved in collisions and not been injured severely enough to warrant hospital attention. With this inherent bias in mind, however, we felt it would still be useful to compare the injury experience of hospital admitted helmeted cyclists with that of an unhelmeted 'reference' group.

Subjects and methods

This study was conducted at the Royal Children's Hospital ( $\mathrm{RCH})$, the principal paediatric centre in Melbourne, which serves a paediatric population of more than one million, with an average of 53000 admissions a year, of which 38000 are emergencies. Patients included in the study were cyclists who sought care in the emergency department at $\mathrm{RCH}$ for a bicycle related head injury with or without associated injuries or were referred from another hospital. They were divided into two groups depending on whether or not the available information indicated that they were wearing a helmet at the time of the accident. In the cases where it was unclear whether the child was wearing a helmet it was assumed that no helmet was used. Note that no information was obtained on helmeted cyclists involved in collisions judged not serious enough to result in hospital admission.

Head injury was defined as an injury either to the scalp, skull, brain, or brain stem. A brain
Correspondence to: Dr Nolan. 
injury was defined as concussion (or worse). Minor brain injury included headache, dizziness, nausea, or other minor symptoms resulting from the event. Injuries to the forehead and ears were included in the facial injury group, according to the body region breakdown of the abbreviated injury scale (AIS), 1990 revision. ${ }^{14}$

Patients were identified through the Victorian Injury Surveillance System (VISS) which is an all-age, all-injury hospital emergency department based surveillance system that uses standardised injury codes. ${ }^{1}$ The codes used to identify head injured cyclist patients were: injured body part codes: skull base (107), skull vault (108), other injury to the head (196), brain (701), and brain stem (702); nature of the injury code: concussion (96); context of the injury codes: bicyclist (102), and bicyclist passenger (103). Children less than 15 years of age were selected, for the period extending from 1 January 1988 to 30 April 1992.

All records were reviewed by a paediatric orthopaedic surgeon (GG). During the study, 228 children who had a cycling accident and attended the emergency department for a head injury were identified by VISS. Of these, 39 were excluded because either the accident occurred within the home ( 36 cases), or the trauma resulted from a tricycle accident (three cases).

The AIS was used to assess the severity of injuries by calculating an injury severity score (ISS) for each patient. ${ }^{14-16}$ The severity score given to the head and neck area was designated ISSH, and the relative contribution of the head injury score to the total severity score was assessed by the ratio ISSH/ISS. Proportions were compared by $\chi^{2}$ tests with Yates's correction. Mean differences were assessed by Student's $t$ test. All $\mathrm{p}$ values quoted are two tailed and statistical significance was taken as $\mathrm{p}<0.05$.

Results

Over the study period, there was a substantial reduction in the number of head injuries to children not wearing a helmet (figure). At the same time, there was a slight increase in the number of head injuries among children wearing a helmet.

\section{HELMET GROUP}

During the 52 months of the study, 34 children in the helmet group were treated in the emergency department. Boys comprised almost three quarters of the cases ( 25 children). Mean (SD) age was $10 \cdot 7(2.5)$ years for the boys and $9 \cdot 1(2 \cdot 3)$ years for the girls $(p=0 \cdot 10)$. Table 1 shows the characteristics of the head injuries. The majority involved the brain $(94 \%)$. The severity of the injury was usually mild - 26 cases $(76 \%$ ) being graded 2 on the AIS. Seven children had a severe injury, graded 4 or higher. Two deaths occurred within two days of admission among this group of severely injured patients.

The nature of head injuries ranked by severity according to AIS is given in table 2 . Eleven children (32\%), had two or more injuries to the head. About $40 \%$ of the patients had loss of consciousness, $29 \%$ an injury to the brain stem, cerebrum or cerebellum, and $24 \%$ a concussion.

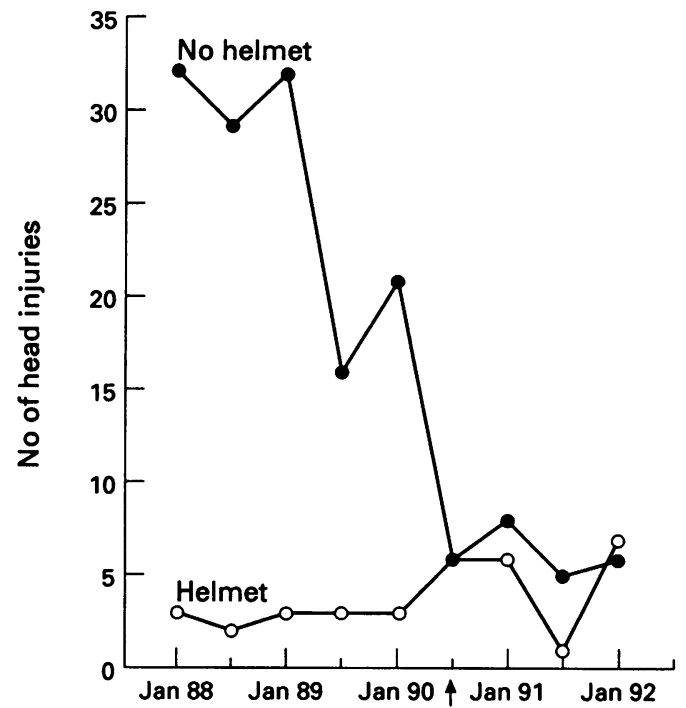

Secular trend of head injuries. The data points indicate numbers of child bicyclists attending $\mathrm{RCH}$ with head injury in the six months after the date on the axis. The mandatory helmet law was introduced on 1 fuly 1990 (arrow).

Table 1 Characteristics of head injuries

\begin{tabular}{|c|c|c|c|c|}
\hline \multirow[t]{2}{*}{ Injury } & \multicolumn{2}{|l|}{ Helmet } & \multicolumn{2}{|l|}{ No helmet } \\
\hline & No $(\%)$ & Severity score ${ }^{\star}$ & No $(\%)$ & Severity score ${ }^{\star}$ \\
\hline $\begin{array}{l}\text { Type } \dagger \\
\text { All } \\
\text { Scalp injury } \ddagger \\
\text { Minor brain injury } \S \\
\text { Skull fracture } \\
\text { Brain (concussion or worse) } \\
\text { Deaths }\end{array}$ & $\begin{array}{l}34(100) \\
1(3) \\
0 \\
1(3) \\
32(94) \\
2(6)\end{array}$ & & $\begin{array}{l}155(100) \\
0 \\
40(26) \\
13(8) \\
102(66) \\
8(5)\end{array}$ & \\
\hline $\begin{array}{l}\text { Severity } \\
\text { No loss of consciousness but headache or dizziness; scalp contusion } \\
\text { Amnesia; concussion; lethargic; loss of consciousness }<1 \text { hour } \\
\text { Displaced vault or basilar fracture; mild brain swelling } \\
\text { Intraventricular haemorrhage; small subdural or intracerebral haematoma } \\
\text { Large extradural haematoma; severe brain oedema } \\
\text { Penetrating injury or laceration of the brain stem; dislocation above C3 }\end{array}$ & $\begin{array}{l}1(3) \\
26(76) \\
0 \\
5(15) \\
2(6) \\
0\end{array}$ & $\begin{array}{l}1 \\
2 \\
3 \\
4 \\
5 \\
6\end{array}$ & $\begin{array}{l}40(26) \\
82(53) \\
12(8) \\
10(6) \\
10(6) \\
1(1)\end{array}$ & $\begin{array}{l}1 \\
2 \\
3 \\
4 \\
5 \\
6\end{array}$ \\
\hline
\end{tabular}

^Severity score according to the AIS

tThe diagnosis of head injury used was the most severe in the case of multiple head injuries.

¥Scalp injury includes contusions, abrasions, and superficial haematomas.

$\S$ Minor brain injury includes headache, dizziness, nausea, or other minor symptoms resulting from head trauma. These injuries are graded as 1 on ISS. 
Table 2 Number ( $\%$ ) of patients with head injuries

\begin{tabular}{lcc}
\hline Diagnosis & $\begin{array}{c}\text { Helmet } \\
(n=34)\end{array}$ & $\begin{array}{c}\text { No helmet } \\
(n=155)\end{array}$ \\
\hline Dislocation C2-C3 & 0 & $1(1)$ \\
Brain stem/cerebrum/cerebellum† & $10(29)$ & $26(17)$ \\
Thrombosis internal carotid artery & $1(3)$ & 0 \\
Fracture of the skull $\downarrow$ & $6(18)$ & $25(16)$ \\
Contusion of 6th cranial nerve & 0 & $1(1)$ \\
Loss of consciousness & $13(38)$ & $35(23)$ \\
Concussion & $8(24)$ & $9(6)$ \\
Amnesia & $3(9)$ & $32(21)$ \\
Minor brain injury§ & $1(3)$ & $40(26)$ \\
Lethargy/stupor/obtunded & $1(3)$ & $4(3)$ \\
Scalp injury & $7(21)$ & $31(20)$ \\
\hline
\end{tabular}

*Diagnoses are ranked by severity accordingly to the AIS Diagnoses were either contusion, oedema, laceration, intraventricular hemorrhage, or haematoma.

tSkull fracture includes fracture of the base of the skull and vault. Two helmeted children had two fractures and one non-helmeted.

\$Minor brain injury includes headache, dizziness, nausea, or other minor symptoms resulting from head trauma.

$\checkmark$ Scalp injury includes abrasion, contusion, and laceration.

Table 3 shows the injuries to body parts other than the head. All children had at least one such injury. The limbs were the most frequent site of these injuries, followed by the face. Facial injuries occurred in 22 patients, of whom six had one or more fractures. A total of 33 fractures either affecting the limbs, face, or spine occurred in 16 children. One case of cervical spine fracture occurred. There was no evidence that any injury resulted from the helmet itself.

The accident circumstances are presented in table 4. In $71 \%$ of cases the time of the accident was between 3 and $6 \mathrm{pm}$ and $85 \%$ occurred on asphalt or a concrete road. In about one third of the accidents, the bicycle collided with a car, while in another one third the accident was described as a fall to the ground. The helmet was lost on impact in $15 \%$ of the events, but the severity of head injury was similar in these cases to those who did not lose their helmet. Alcohol was not associated with any injury event.

About two thirds of the severity of all injuries was accounted for by the head injury, as indicated by the ISSH/ISS ratio (table 5). Three quarters of the patients were admitted to hospital, although only $15 \%$ were hospitalised for one or more weeks. Some form of diagnostic evaluation (usually a radiograph) was carried out in $75 \%$ of the children. Twenty nine per cent underwent a surgical procedure.

\section{NO HELMET GROUP}

During the same period, 155 children in the no helmet group were injured, $65 \%$ of whom were boys with a mean (SD) age $10 \cdot 2(2 \cdot 8)$ years very similar to the mean of $10.6(3.2)$ years for the girls $(p=0.47)$. More than one quarter of these children had a minor head injury (table 1). Eight patients died as a result of their head injury. Table 2 shows the head injuries sustained by the children and table 3 the injuries to the other body parts. There were 34 children with injuries involving the head only, and 45 $(29 \%)$ had two or more head injuries. The accident circumstances were similar to the helmet group (table 4), although the proportion of falls to the ground was higher. The head
Table 3 Number ( $\%$ ) of patients with injuries to other body parts

\begin{tabular}{|c|c|c|}
\hline Injuries & $\begin{array}{l}\text { Helmet } \\
(n=34)\end{array}$ & $\begin{array}{l}\text { No helmet } \\
(n=155)\end{array}$ \\
\hline $\begin{array}{l}\text { Facial } \\
\text { Superficial`} \\
\text { Fracture } \\
\text { Nerve } \\
\text { Total } \dagger\end{array}$ & $\begin{array}{l}21(62) \\
6(18) \\
0 \\
22(65)\end{array}$ & $\begin{aligned} & 72(46) \\
& 18(12) \\
& 1(1) \\
& 74(48)\end{aligned}$ \\
\hline $\begin{array}{l}\text { Chest } \\
\text { Superficial }{ }^{\star} \\
\text { Pneumothorax/rib fracture } \\
\text { Total } \dagger\end{array}$ & $\begin{array}{l}1(3) \\
2(6) \\
2(6)\end{array}$ & $\begin{array}{c}4(3) \\
12(8) \\
16(10)\end{array}$ \\
\hline $\begin{array}{l}\text { Abdominal } \\
\text { Superficial } \\
\text { Visceral } \\
\text { Total } \dagger\end{array}$ & $\begin{array}{l}1(3) \\
0 \\
1(3)\end{array}$ & $\begin{array}{l}3(2) \\
5(3) \\
8(5)\end{array}$ \\
\hline $\begin{array}{l}\text { Spine } \\
\text { Fracture } \ddagger \\
\text { Strain } \\
\text { Plexus brachial } \\
\text { Total } \dagger\end{array}$ & $\begin{array}{l}2(6) \\
0 \\
0 \\
2(6)\end{array}$ & $\begin{array}{l}0 \\
2(1) \\
1(1) \\
3(2)\end{array}$ \\
\hline $\begin{array}{l}\text { Limbs } \\
\text { Superficial` } \\
\text { Fracture } \\
\text { Upper } \\
\text { Lower } \\
\text { Total }\end{array}$ & $\begin{array}{r}21(62) \\
10(29) \\
7(21) \\
4(12) \\
27(79)\end{array}$ & $\begin{array}{l}46(30) \\
17(11) \\
10(6) \\
11(7) \\
60(39)\end{array}$ \\
\hline
\end{tabular}

*Superficial includes lesion to the skin like: abrasion, laceration, or contusion.

†Total denotes the number of patients with at least one lesion. fOne fracture was located to the cervical spine and the other to the lumbar.

Table 4 Accident circumstances; values are number $(\%)$

\begin{tabular}{lcc}
\hline Characteristic & $\begin{array}{c}\text { Helmet } \\
(n=34)\end{array}$ & $\begin{array}{c}\text { No helmet } \\
(n=155)\end{array}$ \\
\hline $\begin{array}{l}\text { Time } \\
\text { Between } 3 \text { and 6 pm }\end{array}$ & $24(71)$ & $93(60)$ \\
Other & $10(29)$ & $62(40)$ \\
Surface & $29(85)$ & $115(74)$ \\
Concrete or asphalt & $5(15)$ & $40(26)$ \\
Other & & \\
Type of accident & $13(38)$ & $42(27)$ \\
Bike-car & $13(38)$ & $83(54)$ \\
Bike-ground & $4(12)$ & $9(6)$ \\
Bike-bike & $1(3)$ & $2(1)$ \\
Bike-tree & $1(3)$ & 0 \\
Bike-kerb & $2(6)$ & $19(12)$ \\
Other $\dagger$ & & \\
Location of the accident & $23(68)$ & $102(66)$ \\
Road & $5(15)$ & $14(9)$ \\
Footpath & $1(3)$ & $9(6)$ \\
Bicycle track & $5(15)$ & $30(19)$ \\
Other & & \\
Helmet & $5(15)$ & NA \\
Flyoff &
\end{tabular}

*Other surface includes gravel, grass, wooden, and unknown. †Other type includes for bike-truck, bike-bus, bike-motorbike bike-post, bike-train, bike-monkey bar; bike-step, bike-semitrailer, bike-brick wall, and unknown.

†Other location includes footpath, bicycle track, school grounds, playground, car park, BMX-track, velodrome, music bowl, and unknown.

Table 5 Severity of injuries; values are mean (SD) AIS scores

\begin{tabular}{lccl}
\hline Body region & Helmet & No helmet & $p$ Value $\dagger$ \\
\hline Head/neck & $6.9(6.33)$ & $6.3(8.51)$ & 0.64 \\
Face & $0.9(2.84)$ & $0.5(1.16)$ & 0.43 \\
Chest & $0.8(3.10)$ & $0.9(3.28)$ & 0.83 \\
Abdomen & $0.1(0.69)$ & $0.3(1.69)$ & 0.38 \\
Extremities & $1.6(2.44)$ & $0.9(2.52)$ & 0.17 \\
External & $0.5(0.51)$ & $0.4(0.49)$ & 0.49 \\
ISS & $10.7(10.19)$ & $9(11.65)$ & 0.42 \\
ISSH/ISS§ & $0.68(0.179)$ & $0.75(0.216)$ & 0.08
\end{tabular}

*AIS values given are square score.

tp Values indicate the significance of difference in mean between helmet and no helmet group, by $t$ test.

IISS represents the cumulative severity score of all injuries. \&ISSH/ISS denotes the proportion contributed by the head injury score to the total severity score. 
injury contributed $75 \%$ to the total severity score (table 5). Two thirds of the patients were admitted to hospital, and $20 \%$ of them were hospitalised for one or more weeks. A diagnostic evaluation (usually a radiograph) was carried out in $55 \%$ of the children. Twenty three per cent underwent a surgical procedure.

\section{Discussion}

Although many studies have examined injuries among bicyclists, this report is the first to investigate head injuries in helmeted child cyclists. The study reveals that the majority of these injuries among the helmeted group were mild. While our data cannot directly address the question of the effectiveness of helmet wearing in reducing head injury, the dramatic reduction in head injuries that was associated with prelegislation voluntary compliance measures ${ }^{13}$ has not been followed by a period of substantial increase in injury to helmeted cyclists (figure). Helmeted children had, however, at least as many facial injuries as those without helmets. Importantly, there appeared to be no injuries secondary to the helmet itself. There is a need to further explore improvements, including the amount of energy absorbed by the helmet to minimise injuries to the brain.

There are several limitations to this study. The most important is selection bias. ${ }^{17} \mathrm{By}$ choosing a hospital as the source of data the study is biased towards more severely injured children. Many helmeted cyclists involved in accidents may not have been injured at all, or suffered only trivial injuries resulting in presentation to primary care doctors or not to any health provider. Second, a certain amount of misclassification bias ${ }^{17}$ could have occurred between the helmeted and non-helmeted groups. For instance, children could have been misclassified as unhelmeted because of missing data, or misreport by parent or ambulance officer. Finally, because of the retrospective nature of the study, limited information was available on the type, damage to, and goodness of fit of the helmet.

The results of this study are in general accord with previous findings regarding the age and sex distribution, the high proportion of superficial lesions and fractures, time of the accident, length of stay, percentage of surgery performed, and the location of the accident. ${ }^{18-22}$

Although one study has shown the helmet to give some form of protection to the face, ${ }^{23}$ the present report and one other study tend to show no evidence for such a protective effect. ${ }^{24}$ Even if theoretically the helmet can protect the forehead, doubts about its effectiveness in providing facial protection remain, particularly when the helmet is worn on the back of the head, as is often the case. Protection could be improved relatively easily, without additional discomfort and without increasing the warmth of the helmet, by adding a modified face guard similar to that used by North American football players.

Another important finding in relation to helmet design is the percentage of helmets lost on impact. A similar proportion, $20 \%$, was found by Acton in her observational study conducted in Brisbane (C Acton et al. Bicycle accidents in young children: the effect of new safety helmet legislation in Queensland. Poster presented at the Second World Conference on Injury Control, Atlanta, USA; 1993). A recent survey in Victoria estimated the proportion of people riding with an unfastened helmet to be up to $4 \%$, at sites on the approaches to secondary schools, ${ }^{25}$ but whether we can generalise from this finding is not clear and the adequacy of fastening was not examined. The adequacy of fit, and the way the straps are placed on the helmet, may be significant factors, and suggest the need to search for a better passive mechanism to secure the helmet.

Although the present study cannot assess the issue of the effectiveness of the helmet, indirect evidence such as the dramatic decline in the number of head injuries after the implementation of the law requiring that all bicyclists wear a safety helmet, is consistent with the effectiveness shown by other studies. ${ }^{2627}$

Finally, it is noteworthy that $26 \%$ of the injuries occurring in the non-helmeted group of children were very minor. It is thus likely that many of these cases would not have attended the hospital if a helmet had been worn. Interestingly, if we exclude these patients from the analysis (patients with a minor brain injury), the mean difference in the ISSH/ISS ratios becomes statistically significant $(p=0.03)$ indicating that more severe head injury occurred in the non-helmeted group of children. We thank Fairlie Nassau and Pat Rogerson from Vic Roads for their help, and the staff of the Victorian Injury Surveillance System (VISS) at the Roy

assistance in extracting data.
Dr Grimard was partially supported by a grant from Le fonds Dr Grimard was partially supported by a grant from Le fonds
de la recherche en santé du Québec and the Royal Children's Hospital Research Foundation.

1 Nolan T, Penny M. Epidemiology of non-intentional injuries in an Australian urban region: results from injury urveillance. $\mathcal{F}$ Paediatr Child Health 1992; 28: 27-35.

2 McFarlane JP, Jones JE Lawson JS. Injuries from bicycle accidents. The problem and recommended strategies for prevention. Aust Paediatr $\mathcal{F}$ 1982; 18: 253-4.

3 Reynolds R, Cohen D. Children, bicycles and head injuries. Med f Aust 1987; 146: 615.

4 McCarthy M. Pedal cyclists, crash helmets and risk. Public Health 1991; 105: 327-34.

5 Nixon J, Clacher R, Peam J, Corcoran A. Bicycle accidents in childhood. $B M \mathcal{F} 1987 ; 294: 1267-9$.

6 Bouvier R. Bicycle accidents in childhood: social and preventive aspects. Aust Fam Physician 1984; 13: 287-9.

preventive aspects. Aust Fam Physician 1984; 13: 287-9.
7 Fife D, Davis J, Tate L, Wells JK, Mohan D, Williams A. Fatal injuries to bicyclists: the experience of Dade Fatal injuries to bicyclists: the experience
County, Florida. $\mathcal{7}$ Trauma 1983; 23: $745-55$.

8 Guichon DMP, Myles TS. Bicycle injuries: one-year sample in Calgary. $\mathcal{F}$ Trauma 1975; 15: 540-6.

9 Ivan LP, Choo SH, Ventureyra ECG. Head injuries in childhood: a 2-year survey. Can Med Assoc $\mathcal{F}$ 1983; 128: $281-4$.

10 O'Rourke NA, Costello F, Yelland JDN, Stuart GG. Head injuries to children riding bicycles. Med $\mathcal{F}$ Aust 1987; 146: 619-21.

11 Klauber MR, Barrett-Connor E, Marshall LF, Bowers SA. The epidemiology of head injury. A prospective study of Th entire community-San Diego County, California 1978. Am ₹ Epidemiol 1981; 113: 500-9.

12 Vulcan AP, Cameron MH, Watson WL. Mandatory bicycle helmet use: experience in Victoria, Australia. World $\mathcal{f}$ Surg 1992; 16: $1-9$.

13 Cameron MH, Vulgan AP, Finch CF, Newstead V. Mandatory bicycle helmet use following a decade of health datory bicycle helmet use following a decade of health
promotion in Victoria, Australia - an evaluation. Accid promotion in Victoria, Austral

14 Association for the Advancement of Automotive Medicine. The abbreviated injury scale 1990 revision. Des Plaines, IL: AAAM, 1990.

15 Genarelli TA. Analysis of head injury severity by AIS-80. 
Proceedings of the American Association of Automotive Medicine 1980; 24: 147-55.

16 Baker SP, O'Neill B, Haddon W, Long WB. The injury severity score: a method for describing patients with multiple injuries and evaluating emergency care. $\mathfrak{J}$ Trauma 1974; 14: 187-96.

17 Sackett DL. Bias in analytic research. Fournal of Chronic Diseases 1979; 32: 51-63.

18 McKenna PJ, Welsh DJ, Martin LW. Pediatric bicycle trauma. F Trauma 1991; 31: 392-4.

19 Armson CJ, Pollard CW. Child cyclist injuries: a prospective study. Med f Aust 1986; 144: 144-6.

20 Selbst SM, Alexander D, Ruddy R. Bicycle-related injuries. Am $\mathcal{F}$ Dis Child 1987; 141: 140-4.

21 Illingworth CM, Noble D, Bell D, Kemn I, Roche C, Pascoe J. 150 bicycle injuries in children: a comparison with accidents due to other causes. Injury 1981; 13: 7-9.

22 Ballham A, Absoud EM, Kotecha MB, Bodlwala GG. A study of bicycle accidents. Injury 1985; 16: 405-8.

23 Thompson DC, Thompson RS, Rivara FP, Wolf ME. A case-control study of the effectiveness of bicycle safety
helmets in preventing facial injury. Am $\mathcal{F}$ Public Health 1990; 80: 1471-4.

24 Ozanne-Smith J, Sherry K. Bicycle related injuries: head injuries since helmet legislation. Victorian injury surveillance system. Hazard 1990; 6: 1-8.

25 Morgan M, Peberdy J, Rogerson P. Bicycle helmet usage rates in Victoria. Victoria: Vic Roads, Road Safety Division, 1991. (Report No GR91.)

26 Thompson RS, Rivara FP, Thompson DC. A case-contro study of the effectiveness of bicycle safety helmets. $N$ Engl f Med 1989; 320: 1361-7.

27 Wasserman RC, Waller JA, Monty MJ, Emery AB, Robinson DR. Bicyclists, helmets and head injuries: a rider study of helmet use and effectiveness. Am $\mathcal{f}$ Public Health 1988; 78: $1220-1$. 